\title{
Role of Flow Simulation as A Tool for Failure Analysis Induced By Sulfate-Reducing Bacteria
}

\author{
Yudha Pratesa, ${ }^{\mathrm{a}, *}$ Badrul Munir, ${ }^{\mathrm{b}}$

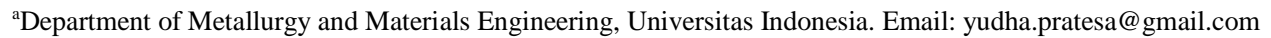 \\ bepartment of Metallurgy and Materials Engineering, Universitas Indonesia. Email: munir@ metal.ui.ac.id
}

\begin{abstract}
Sulphate Reducing Bacteria (SRB) is one of the challenging problems in oil and gas. It could attack the metals to form a pit. The SRB usually left a colony as the indication of corrosion attack. One of the main problems to prevent the corrosion attack is the ability to mapping the possibility of attacking area. However, this study offers a method to simulate the bacterial growth area based on the differential flow rate in the pipe. The flow simulation shows the ability to be used as the analytical tool for the bacterial growth mappings. Scanning Electron Microscope (SEM) and Energy Dispersive Spectroscopy were also conducted for confirmation of the SRB presence in the system
\end{abstract}

Keywords: Corrosion; flow; simulation; sulphate reducing bacterial

\section{Introduction}

One of an offshore platform in java area had a leakage incident. A Leakage incident occurred at 2" elbow pipe at discharge line of gas production. This event repeatedly happened at the elbow on the same line area. Both of leakages occurred adjacent to welding line of pipe body and elbow. This pipe was classified as low carbon steel grade material. It was used to transport mixed fluid which consists of saline water and oil. Fluid analysis indicated the presence of colonies of Sulphate Reducing Bacteria (SRB). Biocide has been given into the material two months before the leak (June to August), and the applied dosages below the recommended level. The fluid flowed intermittently every 30 minutes.

There are several failure analysis studies that are related to microbial induced corrosion (MIC) for example sulfide reducing bacteria (SRB). MIC was found able to attack several types of metals such as stainless steel, steel, copper, and aluminum. Steel is prone to MIC attack compared to the stainless steel due to lower nickel and chromium contents. Surface protection approach that used galvanizing did not give sufficient protection for the SRB attack.

Galvanized steel will suffer local corrosion attack due to selective zinc released [1]. Stainless steel was found corroded by bacterial oxidizing Pseudomonas aeruginosa.

\footnotetext{
${ }^{\star}$ Corresponding author. Tel.: +62-21-786-3510

Kampus Baru Universitas Indonesia, Depok, Indonesia, 16424
}

Pseudomonas Aeruginosa (P.Aeruginosa) biofilm could oxidize the passive film of duplex stainless steel from $\mathrm{Cr} 2 \mathrm{O} 3$ to $\mathrm{CrO} 3$, which highly soluble compound [2]. Another study in stainless steel also found microbial induced corrosion activity increase when bacterial activity is highest, it will minimize the amount of carbohydrate and protein during the process. This microbial corrosion was activated by thermophilic bacterial [3].

Microbial induced corrosion in carbon steel is usually associated with Sulphate Reducing Bacterial (SRB) activity. SRB can form a colony which later forms a biofilm. Biofilms can present the phenomenon of the electrolyte diffuse into the biofilm. This condition is evidenced by the Warburg constant and appearances of phase elements indicates the evolution of the cover films well-formed and the impedance of the layers with time [4].

The system of SRB attack commonly involving at least four components in an environment that is (1) gas, liquid bulk (2), (3) fouling deposits, and (4) substratum. The reaction between the four components using convection and diffusion [5].

As a living being, the SRB requires an ideal condition to create a colony. A colony can be formed at a flow rate of 0.2 $\mathrm{m} / \mathrm{s}$ up to $1.0 \mathrm{~m} / \mathrm{s}$. When flow velocities above $1 \mathrm{~m} / \mathrm{s}$ biofilm layer would be broken, and the SRB is difficult to establish the colony [6]. Besides the velocity, many bacteria can survive at the ambient temperature, but they could not survive at a temperature above $149 \mathrm{~F}$ [7]. 
Many approaches had been proposed for detection and prevention of sulfate-reducing bacteria. J. Starosvetsky [8] used several methods to detect the presence of SRB in the industrial system. He used Energy Dispersive Spectroscopy to analyze the corrosion product and also conduct microbial analysis test to find a number of the microbial in the system. This method had been claimed as a successful method for failure analysis in industrial practice to find out the bacterial absences.

However, this method did not give a better analysis of the location of the sulfate-reducing bacterial where it will attack in the system and why they tend to attack one location than another location. This study will use velocity gradient that showed by finite element methods to find the reason of the preferred location of SRB attack.

\section{Materials and Methods}

This study used low carbon steel with industrial specification API 5L grade B. The methodology was separated into two parts. The first parts are failure analysis methods and the second parts are flow simulation. Both of them will be matched together to find out the correlation between both methods.

The sample was cut using wire cut machine to prevent phase changing. Both of test was conducted after surface preparation with grinding until mesh $600 \#$ to remove the oxide layer. Scanning Electron Microscope and Energy Dispersive Spectroscopy (EDS) analysis were carried out on the surface of material especially an area that covered with white rust.

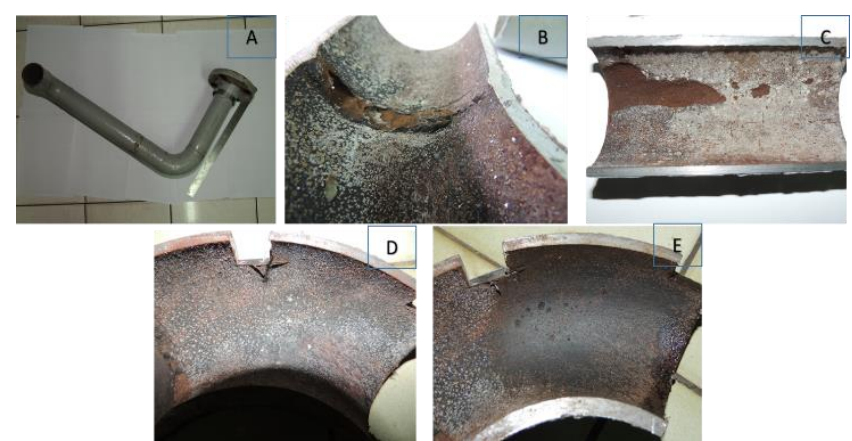

Figure 1. (a) Visual condition of the corroded tubing, (b) section of failed tubing, (c) corrosion at the weldment and straight pipe, (d) condition of

the elbow pipe before cleaning, and (e) pit revealed after cleaning

Finite element analysis was conducted using operational parameter as shown in Table 1.

Table 1. perational parameter for finite element analysis

\begin{tabular}{ccc}
\hline $\begin{array}{c}\text { Velocity } \\
\mathrm{m} / \mathrm{s}\end{array}$ & Temp (F) & Press (psig) \\
\hline 0.15 & 90 & 15 \\
\hline
\end{tabular}

\section{Discussion}

\subsection{Laboratory}

\subsubsection{Visual Examination}

The first step in the examination is a visual examination. As the received sample is a part of tubing pipe that consists of tee pipe, straight pipe, and elbow pipe. (Fig. 2A) The leakage is found near welding area. After internal observation, the leakage was initiated from internal of the pipe (Fig. 2B). It propagated at HAZ area through the welding area. In the internal tubing, a white layer covered the tubing.(Fig. 2C) The denser white layer area is always found together with the corrosion attack at the adjacent area. The exciting findings are the pitting that is found precisely below the white layer. It is revealed after the removing of the white layer (Figs. 1D and 1E). Moreover, if we make a comparison between the elbow and straight pipe, it is found that the elbow had less density of white scale if compared with straight pipe (Figs. 1C and D).

\subsubsection{Microstructructure}

The microstructure was taken from several areas, weld area, Heat Affected Zone (HAZ), Base metal of straight pipe. The results of the microstructure test between pipe $A$ and pipe $\mathrm{B}$ showed similar phase that consists of ferrite and pearlite phase. It showed that there is no issue of microstructure effect on corrosion in the weldment. Acicular ferrite was shown at the weld area, which is typical of fast solidification.

The microstructure of base metal consists of pearlite and ferrite. Based on Fig. 2, corrosion propagated from weld and Heat Affected Zone (HAZ) area. Fig 2. showed leak located at the HAZ 1 while HAZ 2 is in normal condition. It showed the area after the welding cap is a "dead zone area." At this area, the velocity will lower than the other area. This phenomena is the effect of vortex zone area. The leak formed a shallow pit which is indication effect of flow.

Walsh et al.. found the microstructure in weldment could contribute to the rapid microbial induced corrosion attack [9]. Sreekumari et al. also showed the similar result in carbon steel [10]. It showed that weldment microstructure would attack faster than the other area.
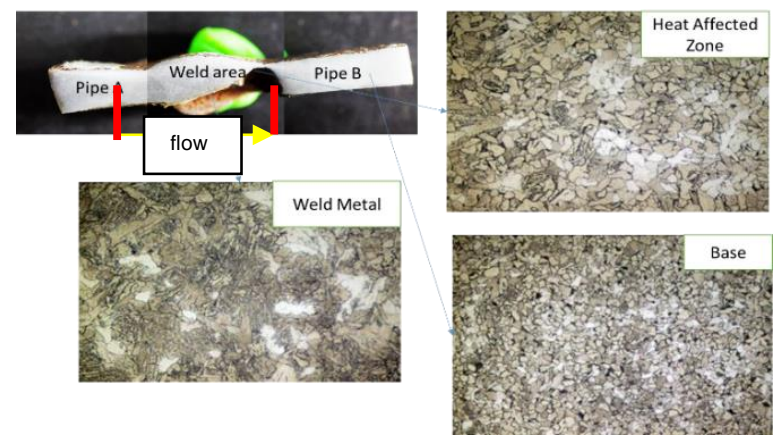

Figure 2. Microstructure of weld area that was attacked by SRB corrosion 
However, our result showed the different result with Sreekumari et al. We found that the microstructure of weldment did not give a significant effect on microbial induced corrosion as shown in Fig. 3. We concluded that the microbial induced corrosion was more affected by the flow pattern in the weldment than the microstructure.

\subsubsection{Scanning Electron Microscope}

Scanning Electron Microscope (SEM) examination was performed at leak area. The results showed microbial activities, indicated by the presence of tubercle and extra polymeric substance (EPS). EPS could accelerate corrosion by binding with metal ions or accelerate iron oxidizing [11]. This EPS will be easier to form in the low velocity area. Fig. 1C showed that the white area consisted of EPS and the colony. The white area covered area around the pit area.

\subsubsection{Energy Dispersive Spectroscopy}

Energy dispersive spectroscopy (EDS) was performed to analyze chemical composition of the Extra Polymeric Substance (EPS). Based on the result, the EPS consisted of Sulphur, carbon, oxygen, and iron. It indicated the activity of bacterial. Calcium and Natrium are not detected in this area. It conforms that the white layer is not a salt precipitation or carbonate scale. On the other hand, the black scale area consists of carbon, oxygen, and iron with small percentage of Sulphur. It showed the black area is an oxide area which did not have any bacterial growth.

Table 2. Energy Dispersive Spectroscopy of SRB

\begin{tabular}{ccccccccc}
\hline & \multicolumn{7}{c}{ Element (\%) } \\
\cline { 2 - 9 } EPS & $\mathrm{C}$ & $\mathrm{S}$ & $\mathrm{O}$ & $\mathrm{Ca}$ & $\mathrm{Na}$ & $\mathrm{Si}$ & $\mathrm{Cl}$ & $\mathrm{Fe}$ \\
\hline Black & 38.1 & $\begin{array}{c}24 . \\
9\end{array}$ & $\begin{array}{c}9.2 \\
5\end{array}$ & n.d & n.d & n.d & n.d & 27.9 \\
scale & 47.6 & $\begin{array}{c}0.4 \\
8\end{array}$ & $\begin{array}{c}28 \\
7\end{array}$ & $\begin{array}{c}3.1 \\
4\end{array}$ & $\begin{array}{c}2.3 \\
8\end{array}$ & $\begin{array}{c}0.7 \\
3\end{array}$ & n.d & 17.0 \\
\hline
\end{tabular}

\subsection{Flow simulation}

Flow simulation analysis was performed using a finite element software. Operational data such as flow velocity, temperature and pressure were used to run this simulation. The flow velocity $(V)$ is taken from the conversion of the production fluid number $(Q)$ that passed through the leaking pipe using Eq. 1.

$$
v(\mathrm{~m} / \mathrm{s})=Q\left(\mathrm{~m}^{3} / \mathrm{s}\right) / A\left(m^{2}\right)
$$

Excessive root weld was simulated as a semicircular dimension with a diameter of $3 \mathrm{~mm}$. The results of this simulation show some areas have a different flow velocity inside the pipe. Those areas were the area that is exposed to the effects vortex phenomenon.

Flow vortices are rotating flow and usually turbulent. Any spiral motion with the direction of flow is called vortices flow. The speed of rotational vortices is zero at the center of vortices flow and increases proportionally according to the distance from its center. This vortex also has a minimum pressure at the center.

Based on the simulation result, it can be seen that the Sulphate Reducing Bacterial (SRB) spread widely around the areas that affected by the vortices especially at the center of the vortices, where the velocity is very low.

The results can be seen in Fig. 3 that showed a significant thinning rate caused by corrosion that is faster than other areas.
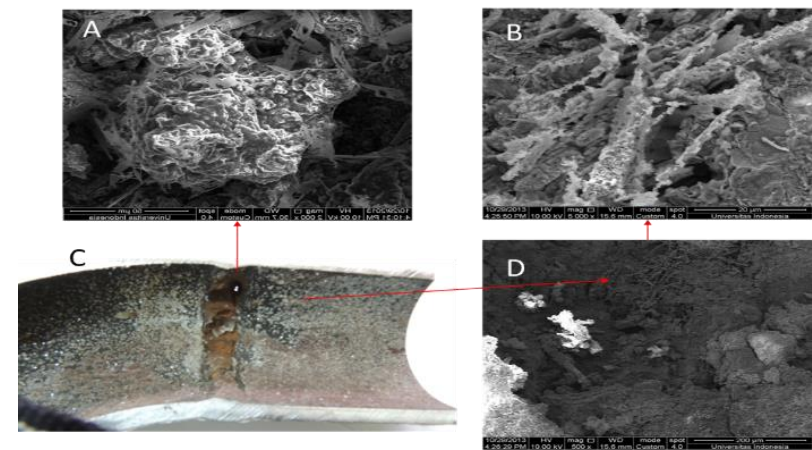

Figure 3. Scanning electron microscope (SEM) analysis at leak position (C) showed Extra Polymeric Substance threads with (B and D) that bind the colony (A)

The reason of occurrence of such mechanisms is the stability of the Sulphate Reducing Bacterial growth rate. The Simulation results also showed that both of these areas had a flow rate below $0.5 \mathrm{~m} / \mathrm{s}$. The value is quite ideal for the growth of bacteria.

Javaherdasti, 2008 also said that the bacteria need a slow velocity for they growing process. The maximum speed is about $0.5 \mathrm{~m} / \mathrm{s}$ so that the colony is stable and Extra Polymeric Substance can be formed

\section{Conclusion}

Flow simulation could help mapping process of Sulphate Reducing Bacterial growth. The laboratory testing confirms the presence of sulfate-reducing bacterial attack as showed by Sulphur and Iron in scale composition. This element is the important substance for Iron Sulphide scale. The flow simulation showed a differences flow rate even in the laminar flow. Differences in flow pattern could help the the colony growth easier in the lower flow rate regime.

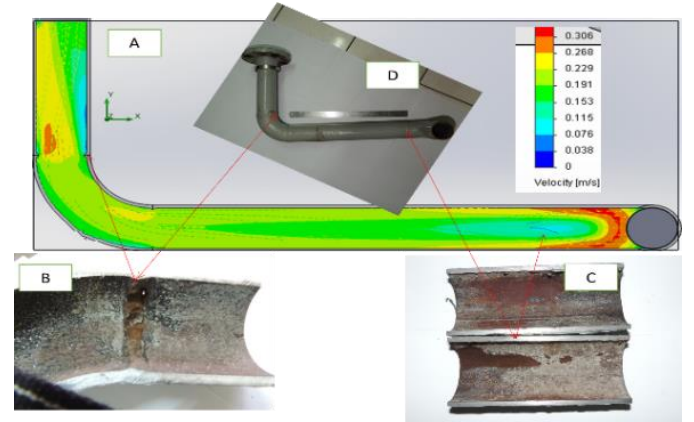

Figure 4. Simulation result showed similar result with the failure area 


\section{References}

[1] N. Bolton, M. Critchley, R. Fabien, N. Cromar, and H. Fallowfield, "Microbially influenced corrosion of galvanized steel pipes in aerobic water systems," J. Appl. Microbiol., vol. 109, no. 1, pp. 239-247, 2010.

[2] E. Zhou et al., "Accelerated corrosion of 2304 duplex stainless steel by marine Pseudomonas aeruginosa biofilm," Int. Biodeterior. Biodegradation, vol. 127, no. November 2017, pp. 1-9, 2018.

[3] S. Lata, C. Sharma, and A. K. Singh, "Microbial influenced corrosion by thermophilic bacteria," Cent. Eur. J. Eng., vol. 2, no. 1, pp. 113-122, 2012.

[4] H. Castaneda and X. D. Benetton, "SRB-biofilm influence in active corrosion sites formed at the steel-electrolyte interface when exposed to artificial seawater conditions," Corros. Sci., vol. 50, no. 4, pp. 1169 1183, 2008.

[5] W. Lee, Z. Lewandowski, P. H. Nielsen, and W. A. Hamilton, "Biofouling: The Journal of Bioadhesion and Biofilm Research Role of sulfate-reducing bacteria in corrosion of mild steel: A review," no. April 2015, pp. 37-41, 2009.
[6] T. Liu, Y. F. Cheng, M. Sharma, and G. Voordouw, "Effect of fluid flow on biofilm formation and microbiologically influenced corrosion of pipelines in oilfield produced water," J. Pet. Sci. Eng., vol. 156, pp. 451-459, 2017.

[7] Javaherdashti R, Microbilogical Influenced Corrosion Handbook. Springer, 2008.

[8] J. Starosvetsky, D. Starosvetsky, and R. Armon, "Identification of microbiologically influenced corrosion (MIC) in industrial equipment failures," Eng. Fail. Anal., vol. 14, no. 8 SPEC. ISS., pp. 1500-1511, 2007.

[9] D. Walsh, D. Pope, M. Danford, and T. Huff, "The effect of microstructure on microbiologically influenced corrosion," JOM, vol. 45, no. 9, pp. 22-30, Sep. 1993.

[10]K. r. sreekumar., "Microbially Influenced Corrosion and Biodeterioration of Structural Metals," Tetsu-to-Hagane, vol. 88, pp. 620-628, 2002.

[11]K. Y. Chan, L. C. Xu, and H. H. P. Fang, “Anaerobic electrochemical corrosion of mild steel in the presence of extracellular polymeric substances produced by a culture enriched in sulfate-reducing bacteria," Environ. Sci. Technol., vol. 36, no. 8, pp. 1720-1727, 2002. 